\title{
Fabrication and tribological properties of superhydrophobic nickel films with positive and negative biomimetic microtextures
}

\author{
Ying WANG ${ }^{1,2,3,4}$, Jing YANG ${ }^{2,3}$, Xiaobao GUO ${ }^{1,2,3}$, Qiang ZHANG $^{4}$, Jingyu WANG $^{4}$, Jianning DING $^{1,2,3,{ }^{*} \text {, }}$ \\ Ningyi YUAN $\mathbf{N}^{1,2,3,4, *}$ \\ ${ }^{I}$ Jiangsu Collaborative Innovation Center of Photovolatic Science and Engineering, Changzhou University, Changzhou 213164, Jiangsu, China \\ 2 Jiangsu Key Laboratory for Solar Cell Materials and Technology, Changzhou University, Changzhou 213164, China \\ ${ }^{3}$ Center for Low-Dimensional Materials, Micro-Nano Devices and Systems, Changzhou University, Changzhou 213164, Jiangsu, China \\ ${ }^{4}$ School of Materials Science and Engineering, Changzhou University, Changzhou 213164, China
}

Received: 22 February 2014 / Revised: 12 May 2014 / Accepted: 06 June 2014

(C) The author(s) 2014. This article is published with open access at Springerlink.com

\begin{abstract}
Nickel (Ni) films with positive and negative textured surfaces of lotus and rice leaf patterns were fabricated through an inexpensive and effective method. The as-prepared Ni films were superhydrophobic and exhibited excellent tribological properties after chemical treatment. Experimental results indicated that the water contact angles (WCAs) on the surfaces of biomimetic textured Ni films (approximately $120^{\circ}$ ) were far greater than those on smooth films $\left(65^{\circ}\right)$. The biomimetic textured surfaces became superhydrophobic (WCA of approximately $150^{\circ}$ ) after perfluoropolyether (PFPE) treatment, which could be due to the combined effects of the special texture and the PFPE. The as-prepared biomimetic-textured Ni films modified with PFPE were improved with a low friction coefficient and excellent antiwear properties, which were due to the combination of the effective lubrication of PFPE and the special textures that served as a good lubricant and a debris reservoir. Moreover, the antiwear properties of the as-prepared $\mathrm{Ni}$ films with negative biomimetic microtextures modified with PFPE were much better than those of films with positive biomimetic microtextures modified with PFPE.
\end{abstract}

Keywords: nickel; positive; negative; bio-mimicking; superhydrophobic; friction

\section{Introduction}

Owing to the outstanding properties of $\mathrm{Ni}$ films, such as hardness, chemical inertness, and wear and corrosion resistance, they have been widely used in microelectromechanical systems (MEMS) and magnetic storage systems [1-6]. As the dimensions of components in MEMS and magnetic storage systems decrease toward the microscale and even the nanoscale, the small size and close spacing of the components can cause serious problems in MEMS operations related to adhesion and friction [7]. Surface chemical

\footnotetext{
* Corresponding author: Jianning DING, Ningyi YUAN.

E-mail: dingjn@cczu.edu.cn, yuanny@cczu.edu.cn
}

modification [8-12] and topographical modification [13-15] are two main approaches to alleviate the problems of adhesion and friction. Recently, a great deal of attention has been paid to perfluoropolyether (PFPE) as an ideal molecular lubricant for MEMS because it has been shown to solve the problem of friction in MEMS devices [10, 16, 17]. Therefore, PFPE was chosen as the chemical modifier in this study.

Functional surfaces with biomimetic microtextures have drawn much interest because of the advantages they offer in many applications, such as their hydrophobic properties, anti-adhesion characteristics, and ability to control friction [17-21]. The natural world offers multiple examples of surfaces that are optimized to control friction through a combination of surface 
texture, orientation, and flexibility, such as the surfaces of a gecko's thumbs and sharkskin [20-24]. Our previous reports found that diamond-like carbon films with lotus-leaf-like biomimetic microtextures exhibited improved tribological behavior [17]. Shafiei and Alpas. demonstrated that bio-textured nickel films could reduce friction [20,21]. Therefore, enhancing surface properties against friction by fabricating surfaces that mimic biotextures will provide a promising technological trend in the future.

This paper reports in detail the development of a simple replication technique that allows specific biotextures to be fabricated in the form of selfsustaining Ni films. For this purpose, the biotextures of lotus leaves and rice leaves were replicated to create Ni surface features that reduce and control frictional forces. The Ni films with positive and negative textures of lotus and rice leaves on the surface were obtained through a combination of replication techniques and electroplating methods.

\section{Experimental}

\subsection{Materials}

The starting materials included biological originals (rice and lotus leaves), polydimethylsiloxane (PDMS; Sylgard 184 Silicone Elastomer Kit, Dow-Corning, USA), PFPE $\left(\mathrm{HOCH}_{2} \mathrm{CF}_{2} \mathrm{O}-\left(\mathrm{CF}_{2}-\mathrm{CF}_{2} \mathrm{O}\right)_{m}-\left(\mathrm{CF}_{2} \mathrm{O}\right)_{n}-\mathrm{CF}_{2} \mathrm{CH}_{2} \mathrm{OH}\right.$, where $m$ and $n$ are integers; molecular weight $=3,800$; commercial name Zdol 3800, Johnson Matthey, USA), and Ni boards (Jiangsu JCMATERIALS Technology Co. Ltd, China). Acetone, nickel sulfate hexahydrate, nickel chloride hexahydrate, boric acid, and sodium dodecyl sulfate, all of which were analytically pure, were used as received. The Ni boards were cleaned with dilute hydrochloric acid solution and deionized water before use. The original locations of the rice and lotus leaves, as well as their corresponding habitats, are shown in Table 1.

Table 1 List of the biological originals examined in this study

\begin{tabular}{ccc}
\hline Species & Locality & Habitat \\
\hline Rice leaf & $\begin{array}{c}\text { Changzhou city, Jiangsu } \\
\text { province }\end{array}$ & $\begin{array}{c}\text { Paddy field, } \\
\text { hydrophily }\end{array}$ \\
Lotus leaf & $\begin{array}{c}\text { Changzhou city, Jiangsu } \\
\text { province }\end{array}$ & Pond, hydrophily \\
& & \\
\hline
\end{tabular}

\subsection{Sample preparation}

The fabrication of a Ni film with biomimetic textures is schematically illustrated in Fig. 1.

\subsubsection{Duplication}

The fresh lotus and rice leaves were placed on a clean glass dish. A mixture of $90.9 \mathrm{wt} \%$ sylgard silicone elastomer 184 and $9.1 \mathrm{wt} \%$ curing agent was poured over the leaves to obtain negative impressions of the textures. The dish containing the covered leaves was left at room temperature for $2 \mathrm{~h}$ to remove bubbles in the solution. It was then placed in an oven at $65{ }^{\circ} \mathrm{C}$ for $10 \mathrm{~h}$ and air cooled at room temperature. After cooling, the textured PDMS film was peeled off of the original template. Negative replicas were obtained on the surfaces of the PDMS films (Fig. 1(c)). Next using the same process, the negative replicas were used as templates to produce positive replicas on the PDMS surfaces (Fig. 1(g)). Finally, all of the PDMS samples with positive and negative biomimetic textures were sputter-coated with a thin layer of gold that had a thickness of approximately $100 \mathrm{~nm}$ to enhance their conductivity for electroplating.

\subsubsection{Electroplating}

Each as-prepared textured polymer with gold film was placed in a $\mathrm{Ni}$ electroplating bath to form a biomimetic metallic layer, following the same procedure
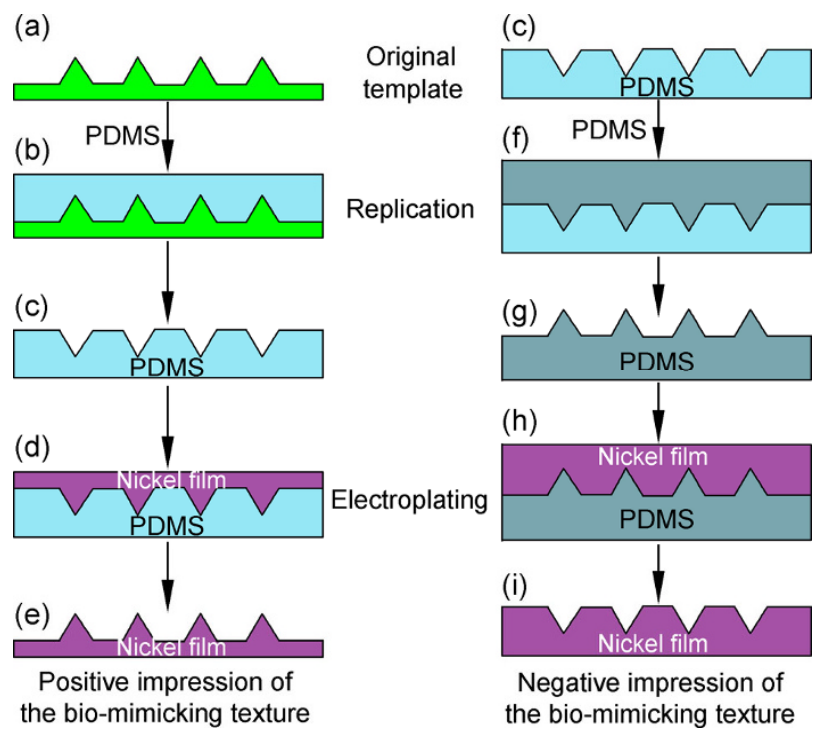

Fig. 1 Schematic illustration for fabricating Ni surfaces with positive or negative surface topographies of biological templates. 
described in our earlier work [19]. The plating time was $2 \mathrm{~h}$ and the current density was $2 \mathrm{~A} / \mathrm{dm}^{2}$. The $\mathrm{pH}$ value of the baths was 4.5-5.5. The plating experiments were conducted at $39 \pm 2{ }^{\circ} \mathrm{C}$. After the electroplating, the PDMS films were peeled off to obtain Ni layers that were approximately $100 \mu \mathrm{m}$ thick with positive or negative impressions of the biomimetic textures (Fig. 1(e) and 1(i)). The Ni films were then rinsed with de-ionized water and dried under a flow of $\mathrm{N}_{2}$. For convenience, we use $\mathrm{N}$ to denote textured $\mathrm{Ni}$ film, $\mathrm{L}$ to denote lotus leaf, and $\mathrm{R}$ to denote rice leaf. Hereafter, the textured $\mathrm{Ni}$ films with positive lotus leaf-like microtexture, negative lotus leaf-like microtexture, positive rice leaf-like microtexture, and negative rice leaf-like microtexture are abbreviated as positive-LN, negative- $\mathrm{LN}$, positive- $\mathrm{RN}$, and negative- $\mathrm{RN}$, respectively.

\subsubsection{Surface chemical modification}

The Ni coatings with positive or negative biomimetic textures were immersed in a dilute solution of $1 \mathrm{mM}$ PFPE in methoxyperfluorobutane (HFE 7100, SigmaAldrich) and kept for $24 \mathrm{~h}$. The samples were then removed from the coating solution and placed in an oven that was kept at $120^{\circ} \mathrm{C}$ for $3 \mathrm{~h}$. Finally, the samples were ultrasonicated in HFE 7100 for $10 \mathrm{~min}$ to remove the physically adsorbed molecules, rinsed with HFE 7100, and dried under a flow of $\mathrm{N}_{2}$. Hereafter, the textured Ni films modified with PFPE are referred to as $\mathrm{NP}$ for convenience. The corresponding textured Ni films with positive lotus leaf-like microtexture, negative lotus leaf-like microtexture, positive rice leaf-like microtexture, and negative rice leaf-like microtexture that were modified with PFPE are referred to as positiveLNP, negative-LNP, positive-RNP, and negative-RNP, respectively.

\subsection{Surface characterization}

The surface morphologies of the biological originals and as-prepared biomimetic textured Ni films were observed on a JSM-5600LV scanning electron microscope (SEM; JEOL, Japan) at $20 \mathrm{kV}$. The surface chemical compositions were examined with a PHI5702 multifunctional X-ray photoelectron spectroscope (XPS; Perkin-Elmer, USA) using $\mathrm{Mg} K_{\alpha}$ radiation as the excitation source. Water contact angles (WCAs) were determined using a contact angle system
(HARKE-SPCA; Beijing Harke, China). A 5- $\mu \mathrm{L}$ droplet was used for the WCA measurements, and average values of at least three repeat measurements for each sample were recorded. Tribological properties were measured using a UMT-2MT tribometer (CETR, USA) under ambient conditions $\left(20-25{ }^{\circ} \mathrm{C}\right.$, relative humidity $=40-50 \%$ ) and a load of $60 \mathrm{mN}$, at a sliding speed of $30 \mathrm{~mm} / \mathrm{s}$ in the reciprocating-sliding mode. The upper counterparts used here were commercially available $440-C$ stainless steel balls (diameter $=6 \mathrm{~mm}$ ). Plots of the friction coefficient (COF) versus time were recorded automatically, and at least three repeat measurements were performed. The images of worn surfaces were obtained using a Contour GT noncontact 3D profilometer (Bruker, Germany).

\section{Results and discussion}

\subsection{Ni films with positive or negative biomimetic surface morphologies}

Typical SEM images of Ni surfaces with positive or negative biomimetic textures are shown in Fig. 2. Figure 2(a) shows an SEM image of positive-LN. It is obvious that the positive surface structures were replicated from the original lotus leaf. Biomimetic textures on the Ni surface were highly uniform: Many micropapillae with diameters ranging from 5 to $10 \mu \mathrm{m}$ were distributed randomly on the surface. An SEM image of negative-LN is depicted in Fig. 2(b). Contrary to the surface of positive- $\mathrm{LN}$, a roughly complementary structure composed of countless micro-orifices with diameters ranging from 6 to $10 \mu \mathrm{m}$ was found on the surface of negative-LN.

Fig. 2(c) is an SEM image of positive-RN. It can be seen that biomimetic textures on the rice leaf surface formed a one-dimensional ordered structure, and papillae and stomata were formed on the surface. As seen in Fig. 2(c), the papillae with diameters of approximately $2-50 \mu \mathrm{m}$ were arranged on the surface. The SEM image of negative-RN in Fig. 2(d) shows that the biomimetic textures on the surface of negative-RN were anisotropic, and micro-orifices and stomatas were formed on the surface. As seen in Fig. 2(d), the micro-orifices had diameters of approximately $2-50 \mu \mathrm{m}$. 


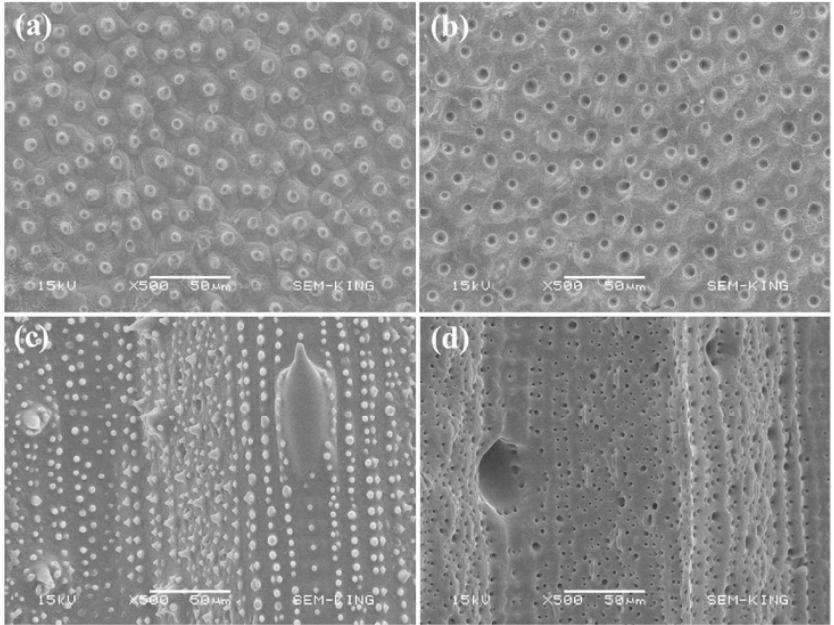

Fig. 2 Typical SEM images: (a) positive-LN, (b) negative-LN, (c) positive-RN, (d) negative-RN.

\subsection{Chemical characterization}

To obtain insight into the chemical composition of the Ni surface modified with PFPE, XPS investigation was performed on the surface, the results of which are shown in Fig. 3. The scan survey spectrum of PFPE shows three elements: fluorine $\left(F_{1 s}\right)$, carbon $\left(\mathrm{C}_{1 \mathrm{~s}}\right)$, and oxygen $\left(\mathrm{O}_{1 \mathrm{~s}}\right)$, the existence of which provides solid evidence that PFPE was adsorbed successfully on the textured surface.

\subsection{Surface hydrophobicity}

The static WCA is a primary parameter that provides a convenient means to assess the relative hydrophobicity of a solid surface. The results measured in this work are shown in Fig. 4. Here the WCAs of the $\mathrm{Ni}$ surfaces with rice leaf-like microstructures were the maximum measured values and were measured in the transverse direction, since the droplets could

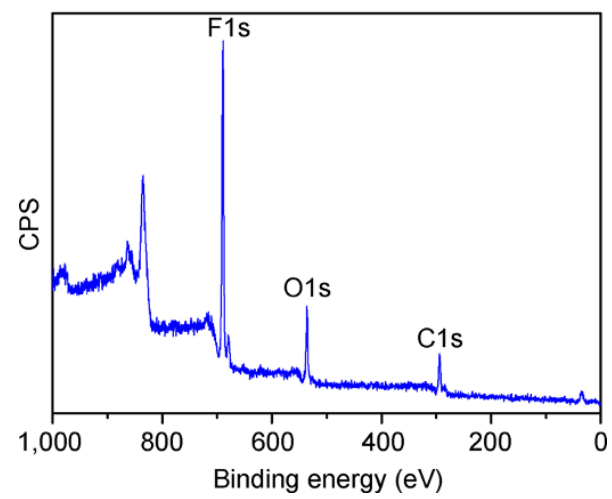

Fig. 3 XPS spectra of textured Ni surface modified with PFPE.

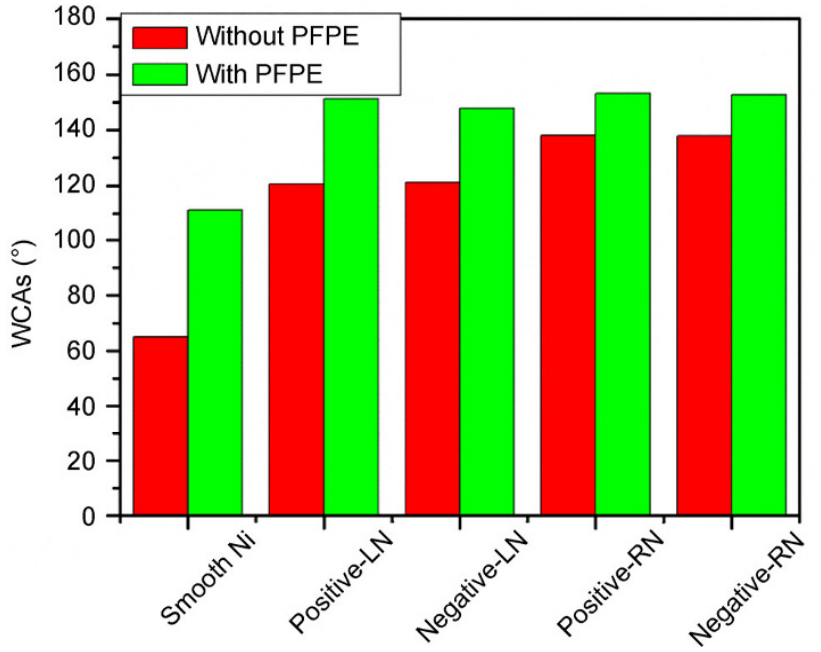

Fig. 4 The WCAs on the surfaces of smooth Ni and the replicas of lotus leaf and rice leaf.

be pinned between the longitudinal grooves [25-27]. Obviously, compared with the WCA of the smooth Ni surface $\left(65^{\circ}\right)$, Ni surfaces with positive biomimetic textures showed much larger WCAs. In particular, after chemical modification with PFPE under a $5-\mu \mathrm{L}$ water droplet, the Ni surfaces with positive biomimetic textures exhibited improved superhydrophobicity $\left(\mathrm{WCA}=151.2^{\circ}\right.$ on positive-LNP; $\mathrm{WCA}=153.2^{\circ}$ on positive-RNP). In addition, the same pattern of change occurred on Ni surfaces with negative biomimetic structures $\left(\mathrm{WCA}=147.9^{\circ}\right.$ on negative-LNP; WCA $=$ $152.7^{\circ}$ on negative-RNP).

It is well known that the WCA of a solid surface depends on several factors, such as surface topography, surface roughness, and surface chemistry. Generally, greater roughness and lower surface energy lead to higher WCAs and higher hydrophobicity. When water droplets are released on a textured sample, air is trapped in the cavities of the rough surface, resulting in a composite solid-air-liquid interface, which leads to a higher contact angle [28]. When the surface energy was decreased by chemical modification in our experiments, PFPE with terminal hydrophobic groups $\left(-\mathrm{CF}_{3}\right)$ led to a higher WCA. It can be clearly seen that the difference in contact angles induced by PFPE treatment was much larger for the textured $\mathrm{Ni}$ films than the smooth film. This was due to the combination effects of a textured surface and the low surface energy of the material, which could yield a contact angle above $150^{\circ}$ and lead to a larger change 
in contact angle as a result $[29,30]$. However, chemical modification of the smooth films using PFPE did not produce WCAs above $120^{\circ}$.

\subsection{Tribological and wear properties}

The microtribological properties of the films were investigated with a ball-on-plate tribometer at a load of $60 \mathrm{mN}$ and a sliding rate of $30 \mathrm{~mm} / \mathrm{s}$, and the results are shown in Figs. 5 and 6. The tribological tests were performed on the surfaces of rice leaf-like microtextured samples in both the transverse and longitudinal directions. However, when a load of $60 \mathrm{mN}$ was set, the actual contact load repeatedly changed from nearly $0 \mathrm{mN}$ to more than $400 \mathrm{mN}$ during sliding in the transverse direction. This large

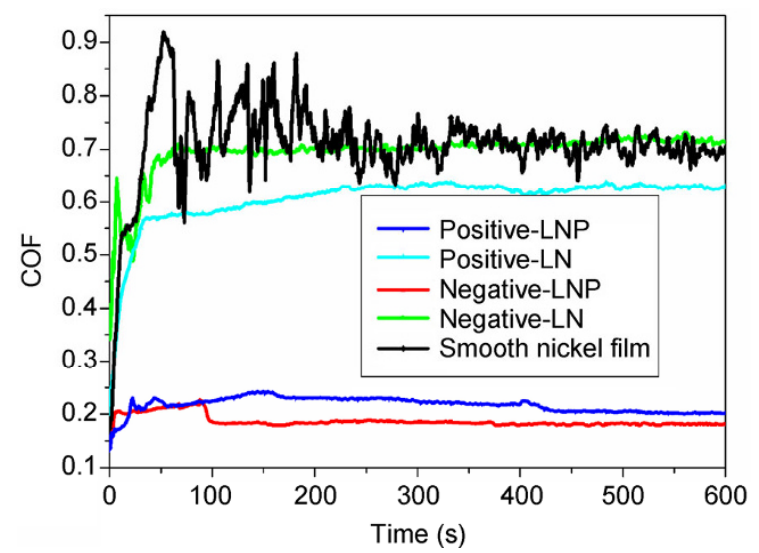

Fig. 5 Variation of Ni films with "lotus leaf"-like micro-texture in COF with time at a normal load of $60 \mathrm{mN}$ and a sliding rate of $30 \mathrm{~mm} / \mathrm{s}$.

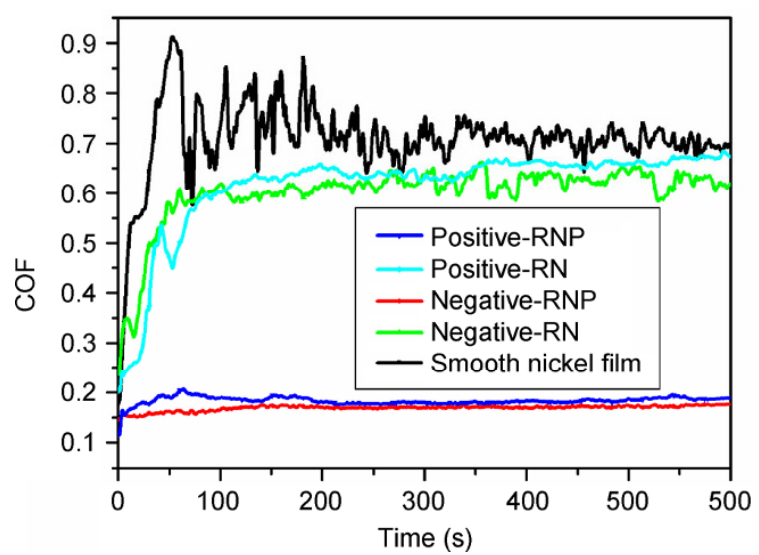

Fig. 6 Variation of Ni films with "rice leaf"-like micro-texture in COF with time at a normal load of $60 \mathrm{mN}$ and a sliding rate of $30 \mathrm{~mm} / \mathrm{s}$. error may have been due to the significant change of structures in the transverse direction, which resulted from the longitudinal grooves. Conversely, the actual contact load remained at approximately $60 \mathrm{mN}$ during sliding in the longitudinal direction. Thus, the tribological results of the rice leaf-like structured samples are presented only in the longitudinal direction. It was observed that the COFs of the textured Ni films were lower than that of the flat film, which could be explained by the fact that the textured Ni films with protrusions and hollows of lotus and rice leaves had smaller contact areas [20].

The wear resistance of the as-prepared textured $\mathrm{Ni}$ coatings (positive-LN, negative-LN, positive-RN, and negative-RN) was still poor. They displayed heavy wear as soon as the counterpart balls began to slide on them, and the COF continued to increase to an average value of approximately 0.7 . However, it was clearly seen that the antiwear abilities of the asprepared $\mathrm{Ni}$ coatings with biomimetic microtextures modified with PFPE (positive-LNP, negative-LNP, positive-RNP, and negative-RNP) were significantly improved. The PFPE remained as an effective lubricant layer for more than $600 \mathrm{~s}$ at a load of $60 \mathrm{mN}$ and a sliding rate of $30 \mathrm{~mm} / \mathrm{s}$. This was due to the combined effects of the lubrication of PFPE and the textured surfaces acting as reservoirs for the lubricant and the wear debris. Moreover, the COFs of the as-prepared Ni coatings with negative biomimetic microtextures modified with PFPE (negative-LNP and negativeRNP) were lower than those of the films with positive biomimetic microtextures modified with PFPE (positive-LNP and positive-RNP). In order to evaluate the endurance of the PFPE-deposited samples, loads of $100-300 \mathrm{mN}$ and a sliding rate of $30 \mathrm{~mm} / \mathrm{s}$ were applied for $1 \mathrm{~h}$. The result of the negative-LNP is shown in Fig. 7 as an example. It was found that the endurance of the negative-LNP was much better than that of the samples without PFPE treatment (Figs. 5 and 7). The PFPE remained as an effective lubricant layer for more than $3,600 \mathrm{~s}$ at a load of $100 \mathrm{mN}$. When the load increased to $300 \mathrm{mN}$, the friction coefficient of the lubricant film increased slowly to approximately 0.6 , indicating the breakdown of the lubricant film.

A 3D non-contact profilometer was used to observe the worn surfaces of the different samples at an applied load of $60 \mathrm{mN}$ and a constant sliding velocity 


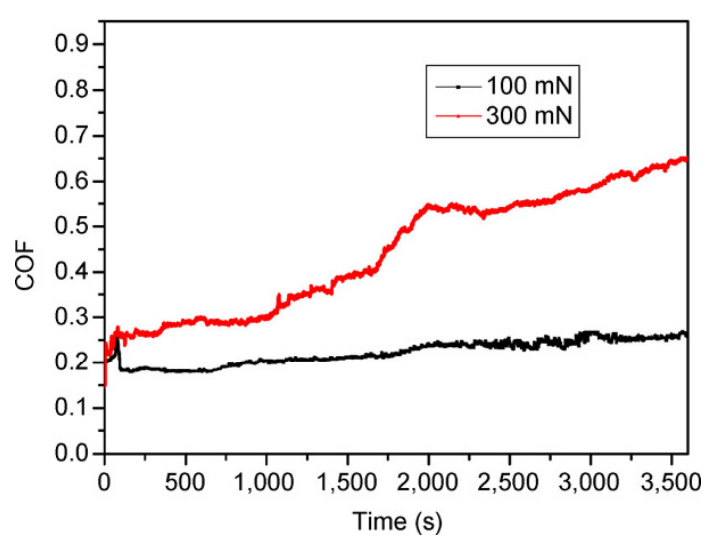

Fig. 7 Variation of Negative-LNP in COF with time at normal loads of $100-300 \mathrm{mN}$ and a sliding rate of $30 \mathrm{~mm} / \mathrm{s}$ for $1 \mathrm{~h}$.

of $30 \mathrm{~mm} / \mathrm{s}$ for $10 \mathrm{~min}$ (Fig. 8). The results showed that the surface textures could trap wear debris from the interface, reducing the plowing and deformation components of friction [31]. On the other hand, the wear particles on the surface of the smooth sample could produce severe scratches, resulting in poor frictional properties.

Among the eight as-prepared textured samples, the unmodified ones exhibited the poorest wear resistance. However, the antiwear performance of the modified samples, which produced less wear debris at the interface, was significantly higher. This obvious difference indicates that PFPE, which has excellent lubricating properties, reduced the contact surface wear for the biotextured films and the textured surfaces could store lubricants and trap wear debris from the interface [20,32]. In other words, the combination of the effective lubrication of PFPE and the textured surfaces resulted in the best tribological behavior. It can also be clearly seen that the antiwear performances of the as-prepared $\mathrm{Ni}$ coatings with negative biomimetic microtextures modified with PFPE (negative-LNP and negative-RNP), which produced less wear debris at the interface, were better than those of coatings with positive biomimetic microtextures modified with PFPE (positive-LNP and positive-RNP). The trend was in accordance with the results of the variation in COF with time, possibly because the negative replicas could store more lubricants and debris than those of the positive replicas.

\section{Conclusions}

Ni films with biomimetic microtextures were obtained through a simple and effective method. Combined with PFPE chemical modification, the as-prepared biomimetic textured Ni films exhibited superhydrophobic properties. The as-prepared biomimetic textured $\mathrm{Ni}$ films modified with PFPE showed improved
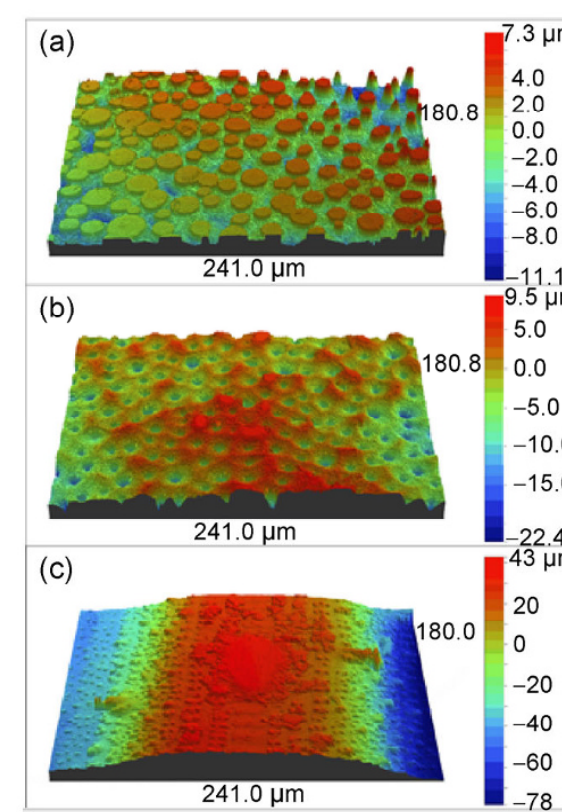
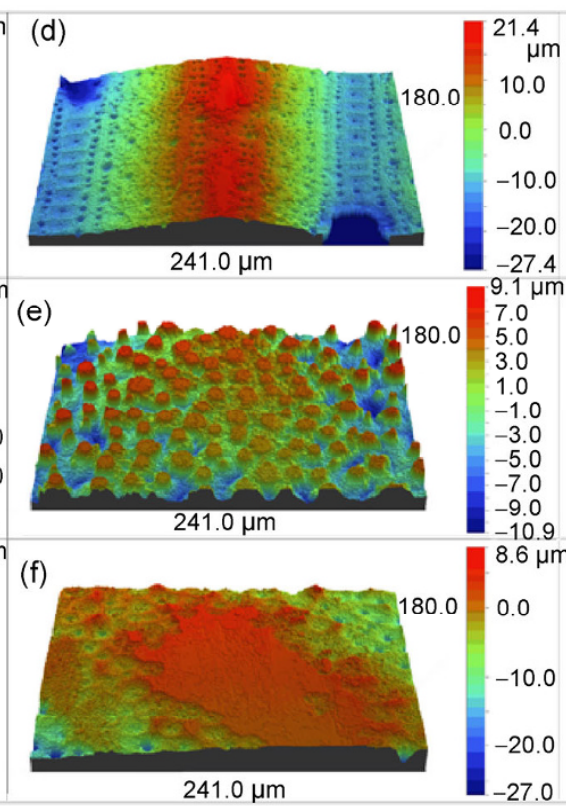

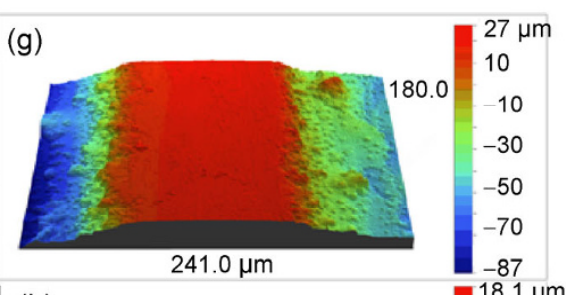

(h)
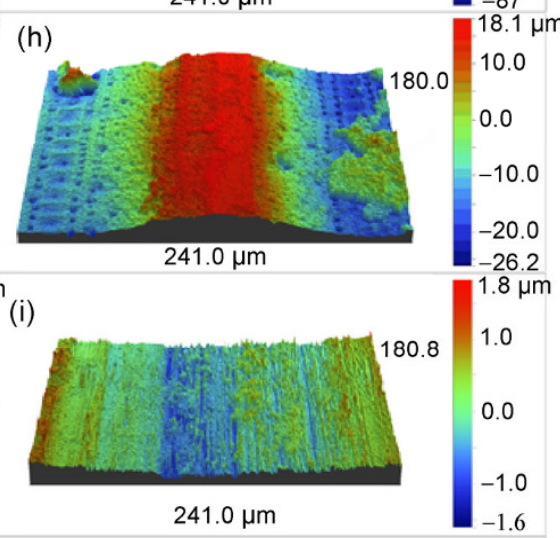

Fig. 8 3D images of different worn surfaces: (a) positive-LNP, (b) negative-LNP, (c) positive-RNP, (d) negative-RNP, (e) positive- LN, (f) negative-LN, (g) positive-RN, (h) negative-RN, (i) smooth nickel film. 
performance with low $\mathrm{COF}$ and excellent antiwear properties, which resulted from the combination of the effective lubrication of PFPE and the biomimetic textures that acted as reservoirs to store lubricant and wear debris. These surfaces with special microtextures are of great importance for both fundamental research and practical applications that require properties such as superhydrophobicity and antiwear.

\section{Acknowledgments}

The authors appreciate the National Natural Science Foundation of China (Nos. 51102028 and 51335002) and acknowledge the financial support of the Priority Academic Program Development of Jiangsu Higher Education Institutions.

Open Access: This article is distributed under the terms of the Creative Commons Attribution License which permits any use, distribution, and reproduction in any medium, provided the original author(s) and source are credited.

\section{References}

[1] Luo J K, Flewitt A J, Spearing S M, Fleck N A, Milne W I. Young's modulus of electroplated Ni thin film for MEMS applications. Mater Lett 58: 2306-2309 (2004)

[2] Leith S D, Schwartz D T. High-rate through-mold electrodeposition of thick ( $>200 \mathrm{~m}$ ) NiFe MEMS components with uniform composition. J Microelectromech S 8: 384-392 (1999)

[3] Mohammadi M, Ghorbani M. Wear and corrosion properties of electroless nickel composite coatings with PTFE and/or MoS2 particles. J Coat Technol Res 8(4): 527-533 (2011)

[4] Ju S P, Wang C T, Chen C H, Huang J C, Jian S R. The nanoindentation response of nickel surfaces with different crystal orientation. Mol Simulat 33: 905-917 (2007)

[5] Liu Y, Yin X M, Zhang J J, Yu S R, Han Z W, Ren L Q. A electro-deposition process for fabrication of biomimetic super-hydrophobic surface and its corrosion resistance on magnesium alloy. Electrochimica Acta 125: 395-403 (2014)

[6] $\mathrm{Gu} \mathrm{C} \mathrm{D}$, Tu J P. One-step fabrication of nanostructured Ni film with lotus effect from deep eutectic solvent. Langmuir 27: 10132-10140 (2011)

[7] Bhushan B, Kulkarni A V, Boehm M, Koinkar V N, Odoni L, Martelet C, Belin M. Microtribological characterization of self-assembled and Langmuir-Blodgett monolayers by atomic and friction force microscopy. Langmuir 11: 31893198 (1995)

[8] Ren S L, Yang S R, Zhao Y P. Micro- and macro-tribological study on a self assembled dual-layer film. Langmuir 19: 2763-2767 (2003)

[9] Gupta R K, Panjwani B, Satyanarayana N, Sinha S K., Srinivasan M P. Ultrathin PFPE film systems fabricated by covalent assembly: An application to tribology. Tribol Lett 45: 371-378 (2012)

[10] Wang Y, Xia L, Ding J N, Yuan N Y, Zhu Y Y. Tribological behaviors of lubricants modified nanoporous anodic alumina film. Tribol Lett 49: 431-437 (2013)

[11] Wang Y, Wang L P, Mo Y F, Xue Q J. Fabrication and tribological behaviour of patterned multiply-alkylated cyclopentanes (MACs)-octadecyltrichlorosilane (OTS) dualcomponent film by a soft lithographic approach. Tribol Lett 41: 163-170 (2011)

[12] Wang Y, Mo Y F, Zhu M, Bai M W. Wettability and nanotribological property of multiply-alkylated cyclopentanes (MACs) on silicon substrates. Tribol Trans 53: 219-223 (2010)

[13] Ando Y, Ino J. The effect of asperity array geometry on friction and pull-off force. J Tribol 119: 781-787 (1997)

[14] Hegemann D, Herwig B, Christian O. Plasma treatment of polymers for surface and adhesion improvement. Nucl Instrum Methods Phys Res 208: 281-286 (2003)

[15] Wang Y, Wang L P, Xue Q J, Yuan N Y, Ding J N. A facile method to improve tribological properties of silicon surface by combining nanogrooves patterning and thin film lubrication. Colloid and Surface A 372: 139-145 (2010)

[16] Sundararajan S, Bhushan B. Micro-electro-mechanical systems/vacuum technology. J Vac Sci Technol A 19: 17771785 (2001)

[17] Wang Y, Wang L P, Wang S C, Wood R J K, Xue Q J. From natural lotus leaf to highly hard-flexible diamond-like carbon surface with superhydrophobic and good tribological performance. Surf Coat Tech 206: 2258-2264 (2012)

[18] Bhushan B, Jung Y C. Natural and biomimetic artificial surfaces for superhydrophobicity, self-cleaning, low adhesion, and drag reduction. Prog Mater Sci 56: 1-108 (2011)

[19] Wang Y, Mo Y F, Zhu M, Bai M W. Wettability of Metal Coatings with Biomimic Micro Textures. Surf Coat Tech 203: 137-141 (2008)

[20] Shafiei M, Alpas A T. Nanocrystalline nickel films with lotus leaf texture for superhydrophobic and low friction surfaces. Appl Surf Sci 256: 710-719 (2009)

[21] Shafiei M, Alpas A T. Fabrication of biotextured nanocrystalline nickel films for the reduction and control of friction. Mater Sci Eng C 28: 1340 - 1346 (2008)

[22] Scherge M, Gorb S. Microtribology of biological materials. 
Tribol Lett 8: 1-7 (2000)

[23] Arzt E, Gorb S, Spolenak R. From micro to nano contacts in biological attachment devices. Proc Natl Acad Sci USA 100: 10603-10606 (2003)

[24] Dean B, Bhushan B. Shark-skin surfaces for fluid-drag reduction in turbulent flow: A review. Phil Trans $R$ Soc $A$ 368: 4775-4806 (2010)

[25] Bixler G D, Bhushan B. Rice- and butterfly-wing effect inspired self-cleaning and low drag micro/nanopatterned surfaces in water, oil, and air flow. Nanoscale 6: 76-96 (2014)

[26] Yao J, Wand J N, Yu Y H, Yang H, Xu Y. Biomimetic fabrication and characterization of an artificial rice leaf surface with anisotropic wetting. Chin Sci Bull 57: 26312634 (2012)

[27] Liu K S, Jiang L. Bio-inspired design of multiscale structures for function integration. Nano Today 6: 155-175 (2011)

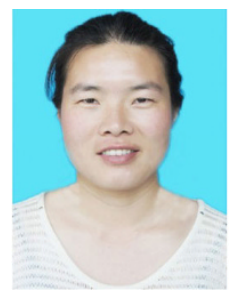

Ying WANG. She received her $\mathrm{PhD}$ degree in Material Science from Lanzhou Institute of Chemical Physics, Chinese Academy of Sciences, Lanzhou,

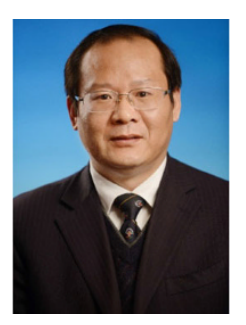

Jianning DING. He received his PhD degree in Mechanical Engineering from Tsinghua University, China, in 2001. He joined Jiangsu University between 1991 and 2007. $\mathrm{He}$ is a research fellow in City University of Hong Kong from 2002 to 2003. His current position is a professor and vice president of Changzhou University. He is the director of center for low- dimensional materials, micro-nano devices and system; director of Jiangsu Collaborative

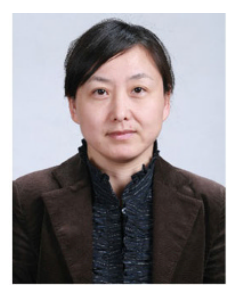

Ningyi YUAN. She received her bachelor degree in Physics in 1988 from Nanjing University, Nanjing, China and $\mathrm{PhD}$ degree in Microelectronics and Solid-State Electronics in 2003 from Shanghai Institute of Microsystem and Information technology, Chinese Academy of Sciences, respectively. She joined Changzhou University
[28] Holgerson P, Sutherland D S, Kasemo B, Chakarov D. Patterning and modification of PDMS surface through laser micromachining of silicon masters and molding. Appl Phys A: Mater Sci Process 81: 51-56 (2004)

[29] Feng L, Song Y, Zhai J, Liu B Q, Xu J, Jiang L, Zhu D B. Creation of super-hydrophobic surface from amphiphilic polymer. Angew Chem Int Ed 42: 800-802 (2003)

[30] Gao Y, Huang Y G, Feng S J, Gu G T, Qing F L. Novel superhydrophobic and highly oleophobic PFPE-modified silica nanocomposite. J Mater Sci 45: 460-466 (2010)

[31] Suh N P, Mosleh M, Howard P S. Control of friction. Wear 175: 151-158 (1994)

[32] Tao Z, Bhushan B. Degradation mechanisms and environmental effects on perfluoropolyether, self-assembled monolayers, and diamondlike carbon films. Langmuir 21: 2391-2399 (2005)

China, in 2010. Since then, she have been working in Changzhou University. Her current research interest is bio-mimicking, multi-scaled micro/nano ultrathin films and micro/nano tribology.

innovation center of "Photovoltaic science and engineering" in 2011; director of Jiangsu Key Laboratory for Solar Cell Materials and Technology; the head of Science and Technology Innovation Team in Jiangsu Universities; the chief scientist in the first level of young and middle-aged in "333 project" of Jiangsu province. His research areas cover the device technology and equipment research of new energy materials, low- dimensional materials, micro-nano devices and system, and Tribology. Above 300 academic papers and 4 books were published.

from 1988. Her current position is a professor and the deputy director of Jiangsu Collaborative innovation center of "Photovoltaic science and engineering", the deputy director of Jiangsu Key Laboratory for Solar Cell Materials and Technology. Her research areas cover the low-dimensional materials and micro-nano devices and system. 